\title{
Effectiveness of Inpatient Treatment on Quality of Life and Clinical Disease Severity in Atopic Dermatitis and Psoriasis Vulgaris - A Prospective Study
}

\author{
Jochen Schmitt Elisabeth Heese Gottfried Wozel Michael Meurer \\ Department of Dermatology, University Hospital Carl Gustav Carus, Technical University Dresden, \\ Dresden, Germany
}

\begin{abstract}
Key Words
Atopic dermatitis • Dermatology Life Quality Index • Disease severity · Eczema Area and Severity Index • Psoriasis vulgaris - Psoriasis Area and Severity Index
\end{abstract}

\begin{abstract}
Background: Financial constraints challenge evidence of the effectiveness of dermatological inpatient management. Objective: To evaluate the effectiveness of hospitalization in atopic dermatitis and psoriasis regarding initial and sustained benefits. Methods: Prospective study on adults with psoriasis vulgaris $(n=22)$ and atopic dermatitis $(n=14)$. At admission, discharge, and 3 months after discharge, validated outcomes of objective and subjective disease severity were assessed by trained investigators. Results: Hospitalization resulted in substantial benefit in quality of life and clinical disease severity. Looking at mean scores, the observed benefit appeared stable until 3-month follow-up. The analysis of individual patient data revealed significant changes in disease severity between discharge and 3-month follow-up with some patients relapsing, others further improving. Reasons for hospitalization and treatment performed were not related to sustained benefit. Conclusions: In psoriasis vulgaris and atopic dermatitis, hospitalization effectively improved quality of life and clinical disease severity. Further research should focus on prognostic factors for sustained improvement.

Copyright $\odot 2007$ S. Karger AG, Basel
\end{abstract}

\section{KARGER}

Fax +4161306 1234

E-Mail karger@karger.ch

www.karger.com
(C) 2007 S. Karger AG, Basel

$1018-8665 / 07 / 2141-0068 \$ 23.50 / 0$

Accessible online at:

www.karger.com/drm

\section{Introduction}

Psoriasis vulgaris (PSO) and atopic dermatitis (AD) are among the most important dermatological conditions in terms of prevalence, health-related quality of life (HRQL) impact, and societal economic burden [1-10]. While most cases of AD and PSO can be effectively controlled with emollients and topical treatments, some patients with extensive disease, outpatient treatment failure, acute deterioration, or highly impaired everyday functioning require inpatient care. Recently, administrative and financial pressures have led to a reduction both in bed numbers and average duration of inpatient treatment [11]. These structural changes in the health services in Europe also led to modifications of the aims of hospitalizing patients with chronic relapsing skin diseases. While previously complete clearance was the goal, we now try to improve the symptoms sufficiently to allow outpatient treatment. In patients with severe AD or PSO, this might be problematic, as the chances of relapsing early after discharge might be high if inpatient management solely focuses on present symptoms.

HRQL is the main outcome from the patient's perspective [7, 12-14]. Highly impaired HRQL is associated with decreased treatment satisfaction and adherence [15-18]. HRQL is significantly more impaired in hospitalized patients than in outpatients [19]. A stable benefit in HRQL after discharge might therefore be the key determinant to 
avoid readmission by increasing the compliance to and therefore the effectiveness of outpatient care.

Recently, it has been shown that hospitalization improves HRQL in patients with PSO and AD $[11,19]$. However, as these studies followed their patients only until 1 week and 1 month after discharge, respectively, the longterm effect of hospitalization on HRQL in patients with $\mathrm{PSO}$ and $\mathrm{AD}$ remains unknown.

We conducted a prospective study on adult patients with PSO and AD. At admission, discharge, and 3 months after discharge, HRQL, clinical disease severity, and selfassessed global disease severity were assessed. Our research questions included whether hospitalization is beneficial for objective and subjective disease severity, and whether disease severity remains stable between discharge and 3-month follow-up visit.

\section{Methods}

\section{Setting and Study Population}

This prospective monocenter study was carried out between July 2003 and May 2004 at the Department of Dermatology, University Hospital Dresden, Germany. The study followed the principles outlined in the Declaration of Helsinki [20].

Eligibility criteria included age of 18 years or older, hospitalization because of PSO or AD, i.e. one of these conditions had to be the referral diagnosis, chronic course of the disease over at least 6 months, and first hospitalization because of one of the studied conditions within the study period.

Out of 62 patients eligible for participation, informed consent was obtained from 36 (58\%; PSO: $\mathrm{n}=22$; AD: $\mathrm{n}=14$ ). Seven eligible patients were not recruited because of admission when none of the investigators was on call, e.g. during the weekend. Nine eligible patients were unwilling to participate because of logistical difficulties, e.g. long geographical distance to the study site. Reasons for nonparticipation remained unclear in 10 eligible patients. Follow-up rate was $81 \%$ (total: $\mathrm{n}=29$; PSO: $\mathrm{n}=16$; $\mathrm{AD}: \mathrm{n}=13$ ). From the 7 patients lost to follow-up, 1 PSO patient died (cause unrelated to PSO); the other 6 patients refused to participate in the follow-up visit after 2 written reminders.

\section{Data Collection}

The study consisted of 3 study visits, which were performed by 2 specifically trained investigators (E.H., J.S.). The baseline visit (first study visit) and second study visit were performed within $24 \mathrm{~h}$ after admission and $24 \mathrm{~h}$ before discharge, respectively. The follow-up visit was scheduled at $12 \pm 2$ weeks after discharge. Sociodemographic characteristics and information on specific personal and family disease history were collected at baseline. Additionally, the reason for hospitalization and the treatment performed during hospitalization were recorded at admission and at discharge, respectively. HRQL, physician-assessed objective disease severity, and patient-assessed global disease severity were recorded at each study visit in order to measure the most important aspects of the dermatologic morbidity.

Effectiveness of Hospitalization in Atopic

Dermatitis and Psoriasis Vulgaris
The Dermatology Life Quality Index (DLQI) was introduced by Finlay and Khan [12] in 1994 to measure HRQL in dermatological patients [21]. It consists of 10 questions considering the domains symptoms and feelings, daily activities, leisure, work and school, personal relationships, and treatment during the previous week. The DLQI score ranges from 0 to 30 with higher scores reflecting worse HRQL. The DLQI has adequate psychometric properties. It has frequently been applied in studies on $\mathrm{AD}$ and PSO [12, 21-23].

Objective clinical disease severity was assessed by means of the Psoriasis Area and Severity Index (PASI) in PSO, and the Eczema Area and Severity Index (EASI) in AD [24, 25]. Both measurements have frequently been applied in clinical trials to define eligibility or to measure efficacy [25-28]. Both intensity and extent of the specific skin lesions are scored separately for 4 anatomical regions (head, trunk, upper and lower extremities) by the physician using Likert scales. When calculating the PASI and EASI, the 4 anatomical regions are valued according to their proportion of the whole integument. The PASI and EASI score both range from 0 to 72 with higher scores indicating higher objective severity $[24,25]$.

Patients were asked to rate their global disease severity on a 10-cm Visual Analogue Scale (VAS) with '0' indicating complete remission, and ' 10 ' indicating highest imaginable severity.

Data Analysis

Baseline characteristics of patients with PSO and AD were summarized by means and standard deviations. The $\chi^{2}$ test/Fisher exact test (binary and ordinal variables), and the $t$ test (continuous variables) were used to compare baseline characteristics by condition; $t$ tests were applied to test whether mean differences in severity scores between study visits were equal to zero.

Our alternative hypothesis was that the mean DLQI score differs clinically significantly between the baseline and 3-month follow-up visit. According to published data, a difference in the DLQI of 5 points was considered clinically relevant from the patient's perspective [22]. With a type I error probability of 0.05 , a 2 -sided statistical test, and an assumed standard deviation of the DLQI difference, the study power was $99.9 \%$ if all patients with complete follow-up $(n=29)$ were considered as a single population. When considering patients with $\mathrm{AD}(\mathrm{n}=13)$ and PSO $(\mathrm{n}=16)$ separately, the study power was 91.1 and $95.9 \%$, respectively [29].

The question whether the mean change in the severity score differs by follow-up status was analyzed using the Wilcoxon matched-pairs signed-rank test. The normality assumption was tested using skewness/kurtosis and Shapiro-Wilk tests [30].

Additionally to mean scores, we also looked at individual patient data and calculated the proportions of patients experiencing clinically relevant changes in disease severity between different study visits. For this purpose, a relevant improvement was defined as a relative decrease in severity score by $20 \%$ or more, and a relevant worsening as a relative increase in severity by $20 \%$ or more. The question whether relevant worsening between discharge and 3-month follow-up visit was related to sociodemographic characteristics, reason for admission, and/or treatment performed during hospitalization was analyzed using logistic regression models. The association of outcomes and length of inpatient treatment was tested by Spearman rank correlation [30]. All statistical analyses were performed using Stata statistical software 8.0 for Windows [31]. 
Table 1. Baseline characteristics by diagnosis $(n=36)$

\begin{tabular}{|c|c|c|c|c|}
\hline Variable & $\begin{array}{l}\text { All patients } \\
(\mathrm{n}=36)\end{array}$ & $\begin{array}{l}\text { PSO patients } \\
(\mathrm{n}=22)\end{array}$ & $\begin{array}{l}\text { AD patients } \\
(\mathrm{n}=14)\end{array}$ & $\begin{array}{l}\text { p value for difference } \\
\text { by diagnosis }{ }^{b}\end{array}$ \\
\hline Females, \% & 47.2 & 50.0 & 42.9 & 0.68 \\
\hline Age (mean $\pm S D)$, years & $46.1 \pm 18.0$ & $54.6 \pm 15.2$ & $32.8 \pm 14.2$ & $<0.01$ \\
\hline Disease duration (mean $\pm S D$ ), years & $30.3 \pm 18.5$ & $31.6 \pm 20.2$ & $28.3 \pm 16.0$ & 0.61 \\
\hline Married, \% & 47.2 & 50.5 & 35.7 & 0.27 \\
\hline Income less than $1,000 \mathrm{EUR} /$ month, $\%$ & 77.1 & 76.2 & 78.6 & 0.87 \\
\hline Positive family history, $\%$ & 44.1 & 45.0 & $42.9^{\mathrm{a}}$ & 0.90 \\
\hline DLQI $($ mean $\pm \mathrm{SD})$ & $16.2 \pm 7.6$ & $15.1 \pm 6.9$ & $18.2 \pm 9.1$ & 0.26 \\
\hline $\mathrm{EASI} / \mathrm{PASI}($ mean $\pm \mathrm{SD})$ & $23.9 \pm 15.6$ & $21.3 \pm 14.6$ & $28.1 \pm 16.7$ & 0.20 \\
\hline Disease severity, VAS (mean \pm SD) & $6.7 \pm 2.2$ & $6.8 \pm 2.5$ & $6.6 \pm 1.7$ & 0.75 \\
\hline
\end{tabular}

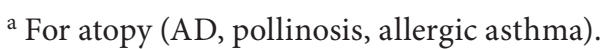

${ }^{\mathrm{b}}$ For difference between patients with $\mathrm{AD}$ and PSO, unpaired t test or $\chi^{2}$ test was performed, as appropriate.

Table 2. Mean differences in objective and subjective disease severity scores between admission and discharge/3-month follow-up visit, and mean differences in severity scores between discharge and 3-month follow-up visit

\begin{tabular}{|c|c|c|c|c|c|c|}
\hline \multirow[t]{2}{*}{ Variable } & \multicolumn{2}{|c|}{$\begin{array}{l}\text { Change from admission to } \\
\text { discharge }(n=36)\end{array}$} & \multicolumn{2}{|c|}{$\begin{array}{l}\text { Change from admission to } \\
\text { 3-month follow-up }(n=29)\end{array}$} & \multicolumn{2}{|c|}{$\begin{array}{l}\text { Change from discharge to } \\
\text { 3-month follow-up }(n=29)\end{array}$} \\
\hline & mean (SEM) & $\begin{array}{l}\mathrm{p} \text { value for } \\
\text { difference }=0\end{array}$ & mean (SEM) & $\begin{array}{l}\mathrm{p} \text { value for } \\
\text { difference }=0\end{array}$ & mean (SEM) & $\begin{array}{l}\mathrm{p} \text { value for } \\
\text { difference }=0\end{array}$ \\
\hline DLQI & $7.7(1.1)$ & $<0.001$ & $9.1(1.5)$ & $<0.001$ & $0.9(1.5)$ & 0.55 \\
\hline EASI/PASI & $13.8(1.9)$ & $<0.001$ & $12.5(2.2)$ & $<0.001$ & $-0.9(2.3)$ & 0.68 \\
\hline Disease severity (VAS) & $2.9(0.5)$ & $<0.001$ & $2.7(0.5)$ & $<0.001$ & $-0.6(0.6)$ & 0.40 \\
\hline
\end{tabular}

Effectiveness of hospitalization is expressed as mean differences in objective and subjective disease severity scores between admission and discharge/3-month follow-up visit (first columns). Stability of benefit is expressed as mean differences in severity scores between discharge and 3-month follow-up visit (last column).

\section{Results}

Sociodemographic and clinical characteristics of the study population at baseline are summarized in table 1 . Except for age, there were no statistically significant differences in socioeconomic characteristics by condition. A positive family history was observed in high proportions of patients with PSO (45.0\%) and AD (42.9\%). Disease severity at admission was high in terms of HRQL impairment, clinical severity, and self-assessed global disease severity. The mean DLQI score of all patients at baseline was $16.2 \pm 7.6$. AD was associated with a nonsignificantly higher impact on HRQL compared to PSO
(AD: $18.2 \pm 9.1$; psoriasis: $15.1 \pm 6.9$ ). Differences in other severity measurements were not statistically significant either, so that all patients could be analyzed as one group for consecutive analyses (table 1). The average duration of hospitalization was $11.3 \pm 5.2$ days in patients with PSO compared to $9.4 \pm 3.3$ days in AD patients $(\mathrm{p}=0.24)$.

The most common reasons necessitating admission were acute deterioration of disease (42.2\%), outpatient treatment failure (38.9\%), and initiation of systemic treatment (13.9\%). Twenty patients (55.6\%) received systemic anti-inflammatory treatment (including UV therapy); the remaining 16 patients (44.4\%) were treated exclusive- 

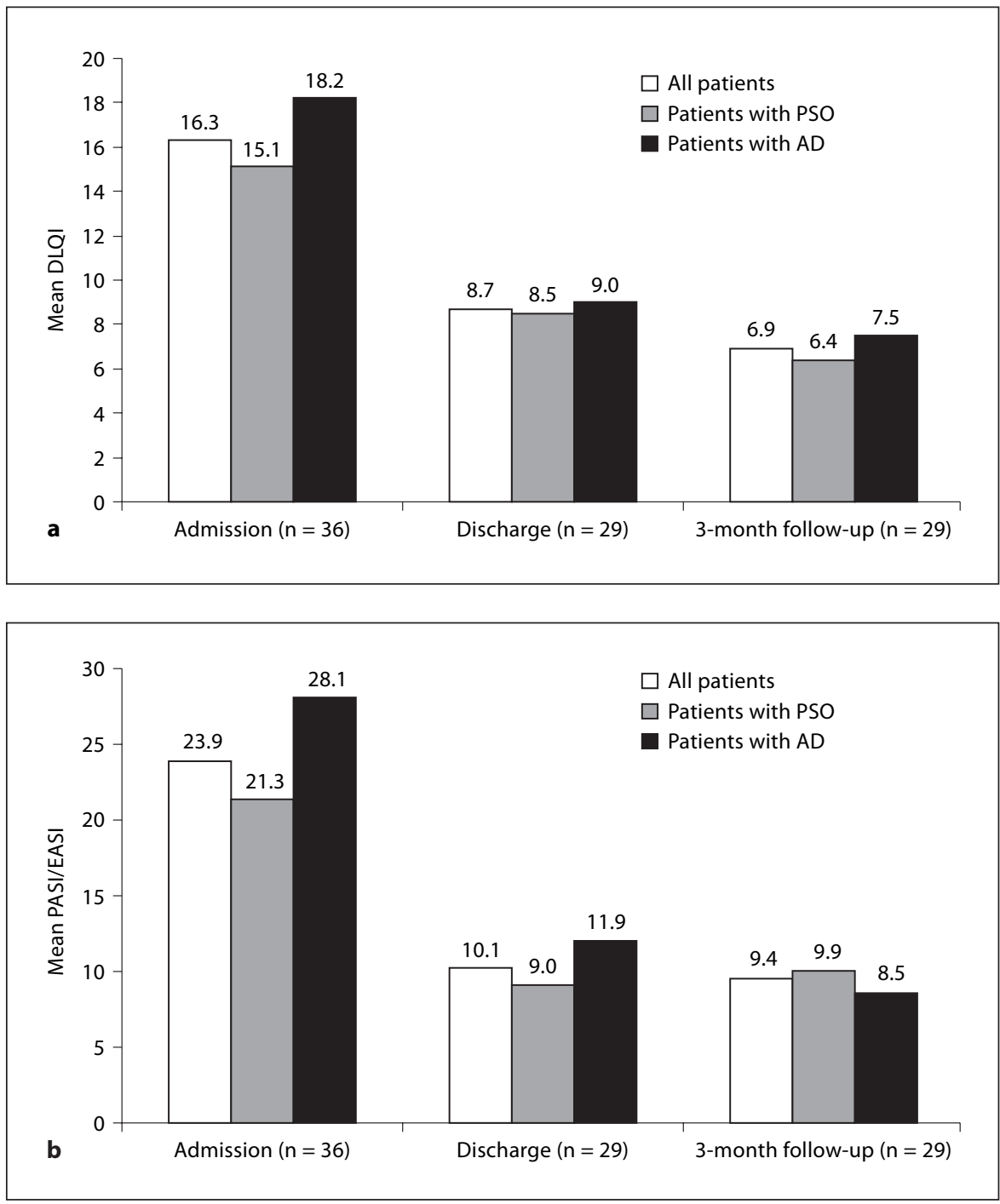

Fig. 1. a Mean DLQI at admission, discharge, and 3-month follow-up by diagnosis. b Mean EASI or mean PASI at admission, discharge, and 3-month follow-up by diagnosis. c Mean self-assessed global disease severity (VAS) at admission, discharge, and 3-month follow-up by diagnosis.

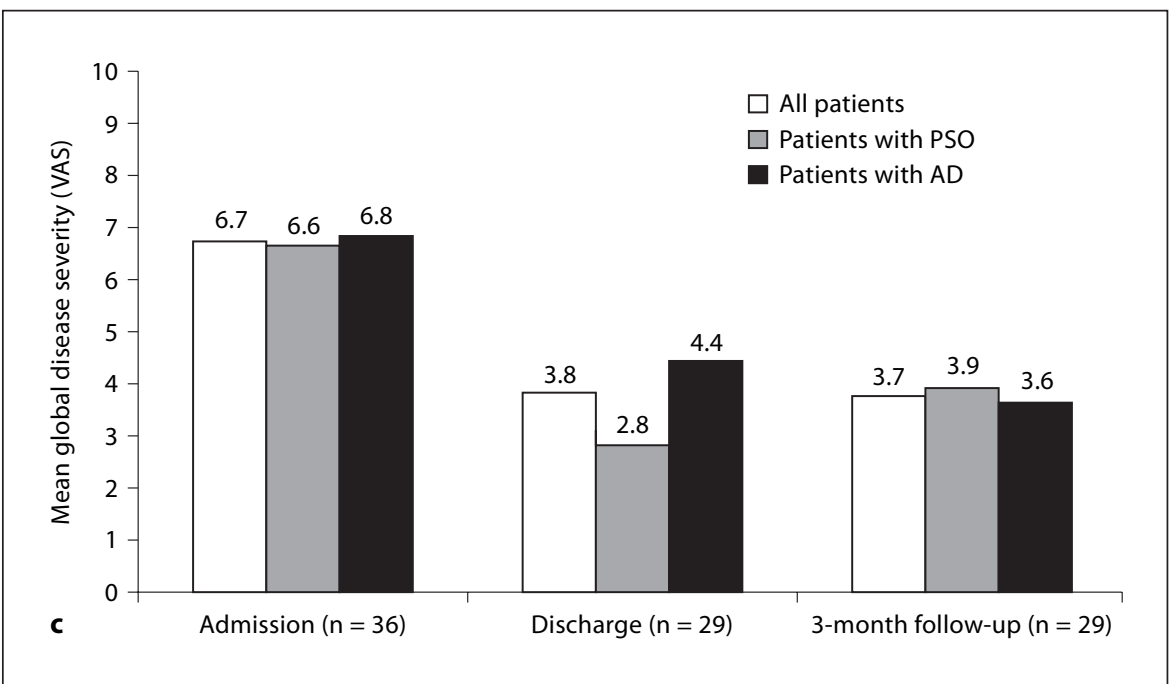


Fig. 2. Mean DLQI scores for HRQL domains at admission, discharge, and 3month follow-up visit.

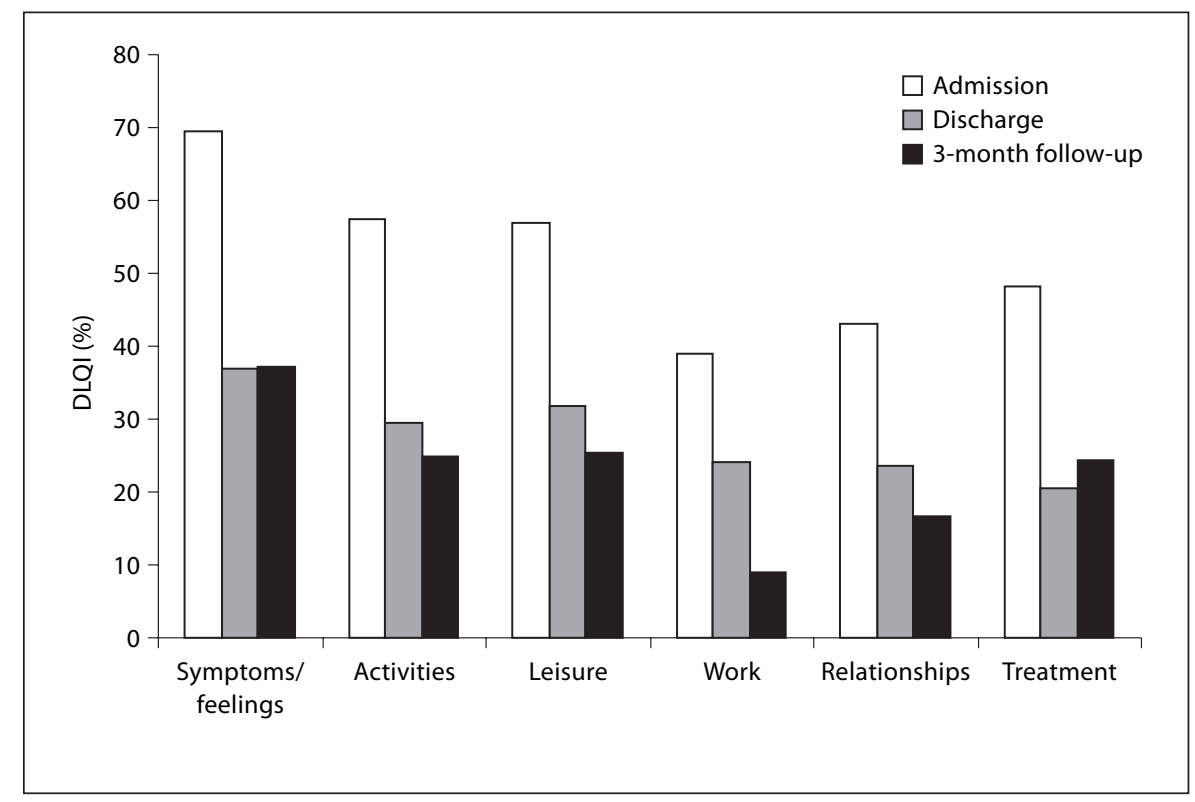

ly with topical agents. Reasons for admission and treatment during hospitalization did not differ significantly by diagnosis.

\section{Analysis of Mean Changes in Outcome Measures}

During hospitalization, the mean DLQI dropped by 7.7 (95\% CI 5.5-9.9). Parallel to the decrease in HRQL impairment, we observed a substantial benefit in terms of both clinical severity, and patient-rated global disease severity (PASI/EASI change 13.8, 95\% CI 10.0-17.6; VAS change $2.9,95 \%$ CI 1.9-3.9; table 2). The magnitude of improvement was comparable between patients with $\mathrm{AD}$ and PSO (fig. 1).

The positive effect of hospitalization on clinical symptoms and HRQL appeared to be stable. This can be concluded for two reasons: firstly, the decrease in all severity measurements between admission and 3-month followup was highly statistically significant $(\mathrm{p}<0.001$ for each score); secondly, there was no statistical difference in any mean outcome measure between discharge and 3-month follow-up visit (table 2).

The duration of hospitalization was neither associated with the benefit in DLQI between admission and discharge $(p=0.36)$, nor with the change in DLQI between admission and 3-month follow-up visit $(\mathrm{p}=0.71)$. There was no statistically significant association either between improvement in HRQL and age $(\mathrm{p}=0.22)$ or income $(\mathrm{p}=$ 0.28 ). The mean change in DLQI between admission and discharge was similar in men and women ( $\mathrm{p}=56$; men: 6.95 points; women: 8.24 points).

As shown in figure 1, the mean changes in outcomes were similar in patients with PSO and AD. Significant and stable benefit was observed in all dimensions of the DLQI (fig. 2).

Differences in benefit from inpatient treatment were similar in patients who completed the follow-up visit and those who did not (decrease in DLQI 7.8 vs. $6.8 ; \mathrm{p}=0.80$; decrease in EASI/PASI 13.7 vs. 14.6; $\mathrm{p}=0.55$; decrease in VAS 3.1 vs. $2.0 ; p=0.51)$. This indicates that selection bias due to dropouts is not present.

\section{Analysis of Individual Patient Data}

High proportions of patients achieved a relevant improvement in HRQL (77.8\%), clinical (97.2\%), and global disease severity (63.8\%) (table 3).

In similarly high proportions of patients, we observed a clinically relevant decrease in disease severity at 3month follow-up compared to admission (DLQI: 79.3\%; EASI/PASI: 86.2\%; VAS: 75.8\%). Only few patients experienced worsening of disease severity during hospitalization (DLQI: 5.6\%; EASI/PASI: 0.0\%; VAS: $2.8 \%$ ) or between admission and 3-month follow-up visit (DLQI: 6.9\%; EASI/PASI: 0.0\%; VAS: 6.9\%) (table 3).

Although the mean change between discharge and 3month follow-up visit was not statistically significant for any outcome, high proportions of patients further im- 
Table 3. Proportion of patients with relevant change in objective and subjective disease severity scores between admission and discharge/3-month follow-up visit, and proportion of patients with relevant change in severity scores between discharge and 3-month follow-up visit

\begin{tabular}{|c|c|c|c|c|c|c|c|c|c|}
\hline \multirow[t]{2}{*}{ Variable } & \multicolumn{3}{|c|}{$\begin{array}{l}\text { Proportion of patients with } \\
\text { relevant change between ad- } \\
\text { mission and discharge, } \% \\
(\mathrm{n}=36)\end{array}$} & \multicolumn{3}{|c|}{$\begin{array}{l}\text { Proportion of patients with } \\
\text { relevant change between ad- } \\
\text { mission and 3-month follow- } \\
\text { up, } \%(n=29)\end{array}$} & \multicolumn{3}{|c|}{$\begin{array}{l}\text { Proportion of patients with } \\
\text { relevant change between dis- } \\
\text { charge and 3-month follow- } \\
\text { up, } \%(\mathrm{n}=29)\end{array}$} \\
\hline & better & equal & worse & better & equal & worse & better & equal & worse \\
\hline DLQI & 77.8 & 16.6 & 5.6 & 79.3 & 13.8 & 6.9 & 51.7 & 6.9 & 41.4 \\
\hline
\end{tabular}

Effectiveness of hospitalization is expressed as the proportion of patients with relevant change (defined as $20 \%$ relative improvement to prior assessment) in objective and subjective disease severity scores between admission and discharge/3-month follow-up visit (first columns). Stability of benefit is expressed as the proportion of patients with relevant change in severity scores between discharge and 3-month follow-up visit (last column).

proved (DLQI: 55.7\%; EASI/PASI: 44.8\%; VAS: 41.6\%), whereas a comparably high proportion experienced relevant worsening of the skin disease (DLQI: 41.4\%; EASI/ PASI: $34.5 \%$; VAS: $45.8 \%$ ) (table 3).

Figure 3 graphically displays the absolute scores in DLQI (fig. 3a) and PASI/EASI (fig. 3b) for every patient separately. Although there is an overall downward trend both in HRQL and clinical severity, the individual response curves show that some patients clearly relapsed until 3 months after discharge. Relevant worsenings of DLQI, PASI or EASI, or global disease severity (VAS) were not associated with any of the ascertained sociodemographic characteristics. The likelihood of relapse was not associated with the diagnosis either (DLQI: $\mathrm{p}=0.34$; PASI/EASI: $\mathrm{p}=0.93$ ).

The duration of hospitalization was neither associated with change in disease severity between admission and discharge, nor with relapse after discharge. Worsening after discharge was neither related with the reason for hospital admission (DLQI: $\mathrm{p}=0.58$; PASI/EASI: $\mathrm{p}=0.76$ ), nor with the treatment performed during hospitalization (DLQI: $\mathrm{p}=0.35$; PASI/EASI: $\mathrm{p}=0.29$ ).

\section{Discussion}

Hospitalization of patients with PSO and AD led to a significant benefit in all relevant dimensions of HRQL. Evidence of effectiveness of inpatient treatment on DLQI was also shown in studies from the USA and UK $[11,19]$.
The extent of DLQI improvement observed in these studies was similar to our sample. Generalizability may be assumed, as the findings from the different settings are consistent. Parallel to the HRQL improvement, we observed significant reductions in clinical disease severity and self-assessed global disease severity. Our conclusion that hospitalization is effective is strong, as it is consistent in both analyses, i.e. when looking at mean changes in scores and at proportions of individual patients achieving relevant improvements.

The presented study extends previous research on the effectiveness of hospitalization as it focuses on the 3month period after discharge. Previous studies had only followed their patients up to 1 month after discharge. Looking at mean scores or at proportions of patients showing relevant relative improvement at 3 months after discharge compared to hospital admission suggests that patients remain in remission. However, looking more precisely at the response curves of individual patients reveals that there is much change both in HRQL impairment and clinical symptoms within 3 months after discharge. Neither length of hospitalization nor sociodemographic characteristics, nor the treatment performed during hospitalization, nor the reason for hospitalization predicted relevant worsening after discharge. Other factors that might explain early relapse include patient's satisfaction with treatment, compliance after discharge, and the degree to which the patient himself was allowed to make an informed choice of the available therapeutic options. Unfortunately, none of these factors was assessed in this or 


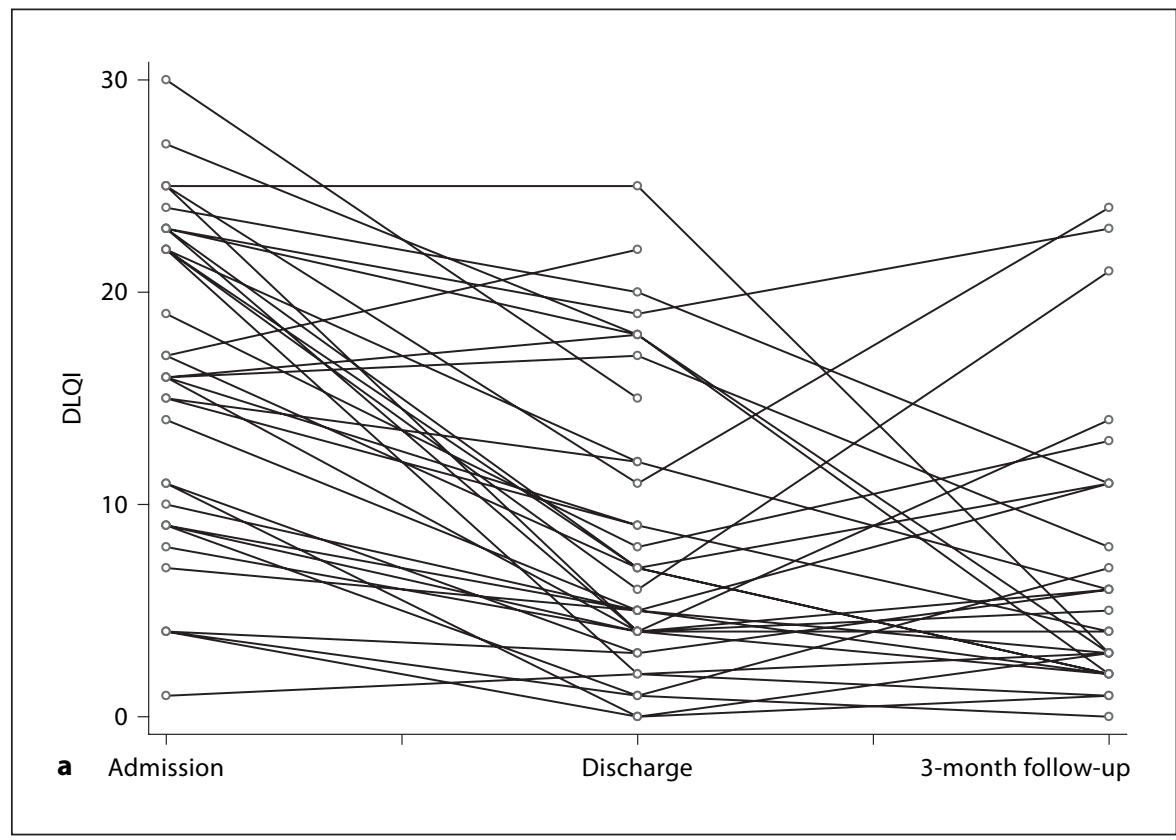

Fig. 3. a DLQI in individual patients at admission, discharge, and 3-month followup. b EASI or PASI in individual patients at admission, discharge, and 3-month follow-up.

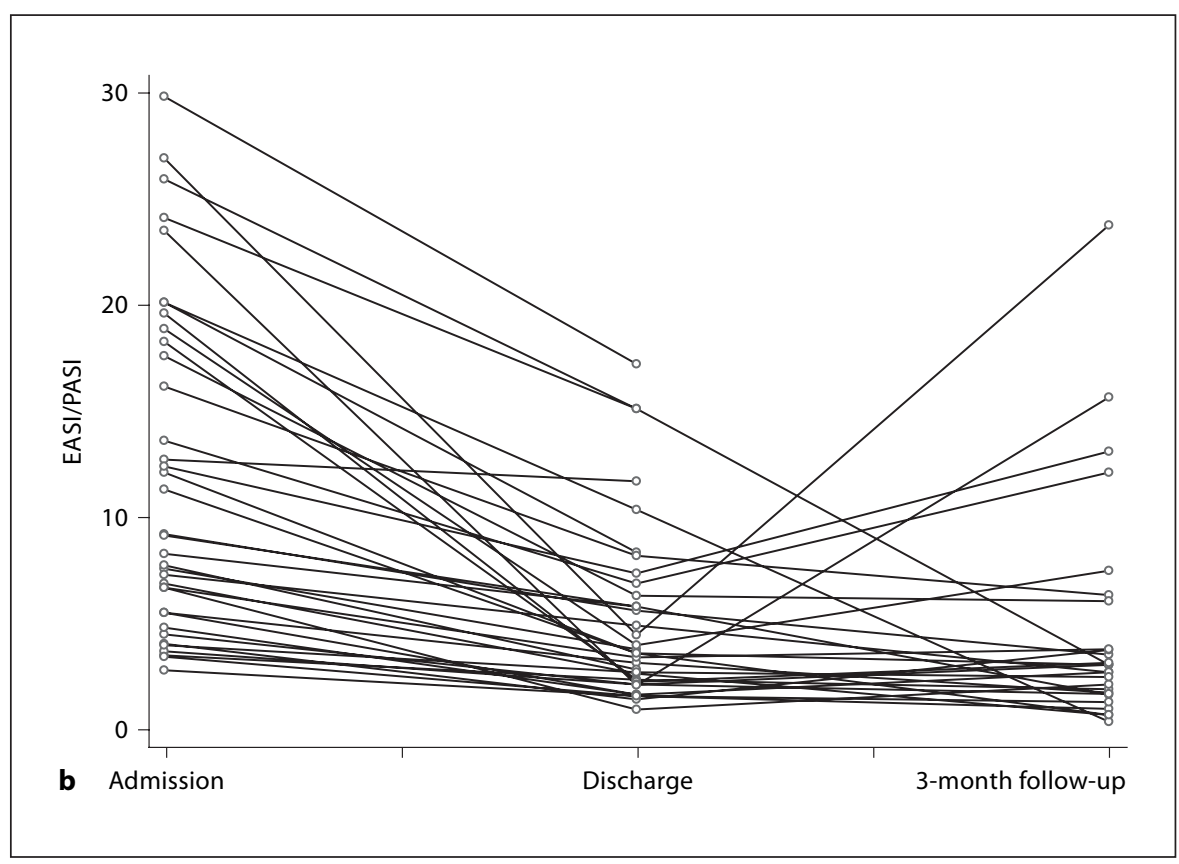

other studies, so that it remains unclear why some patients experienced a relapse early after discharge.

Clearly, there is an overall benefit of hospitalization, which appears to be both substantial and stable for at least 3 months after discharge when analyzing mean scores. All other studies on the effectiveness of hospitalization chose changes in mean scores as outcome $[11,19,32]$. Our study clearly shows that the inference regarding the stability of remission drawn from the whole study population, e.g. changes in mean scores, is contrary to the conclusion drawn from the patients' individual response curves. When applying the results from this study to everyday clinical practice this difference is critically important. The conclusion for the individual patient is that hos- 
pitalization is likely to substantially improve a patient's HRQL as well as the extent and intensity of the skin lesions, but that stable remission is only achieved in a subgroup of patients.

Despite the relatively small sample size, our study was sufficiently powerful to answer our primary research question whether hospitalization leads to a mean improvement in HRQL which is meaningful for the patient.

A possible drawback, however, is that a high proportion of eligible patients could not be recruited. Therefore, the presented data should be interpreted with caution in terms of generalizability. It cannot be excluded that factors affecting the willingness to participate in our study are related to HRQL. However, in most of these cases ( $\mathrm{n}=15,60 \%)$, the reasons for nonparticipation were logistical or organizational, so that we do not think that generalizability is a major concern.

Differences in benefit from hospitalization were similar in patients who completed the follow-up visit and those who did not, indicating that selection bias due to dropouts is unlikely.

Another possible limitation of our study is that no control group was used. The relative importance of dermatological inpatient management should be investigated by comparing inpatient and outpatient treatment protocols.

Further research is necessary to evaluate prognostic factors for sustained improvement. Inpatient treatment protocols that consider such factors are likely to improve the cost-effectiveness of hospitalization. Higher effectiveness of inpatient treatment with sustained benefit after discharge might be achieved by intensively informing and educating the patient during hospitalization. Such interventions might induce a sustained behavior change, better compliance to outpatient treatment options, and overall higher efficiency of dermatological care in general.

\section{References}

1 Finlay AY, Coles EC: The effect of severe psoriasis on the quality of life of 369 patients. $\mathrm{Br}$ J Dermatol 1995;132:236-244.

2 Heydendael VM, de Borgie CA, Spuls PI, Bossuyt PM, Bos JD, de Rie MA: The burden of psoriasis is not determined by disease severity only. J Investig Dermatol Symp Proc 2004;9:131-135.

3 Langley RG, Krueger GG, Griffiths CE: Psoriasis: epidemiology, clinical features, and quality of life. Ann Rheum Dis 2005;64 (suppl 2):ii18-ii23.

4 Naldi L: Epidemiology of psoriasis. Curr Drug Targets Inflamm Allergy 2004;3:121128.

5 Rapp SR, Feldman SR, Exum ML, Fleischer $\mathrm{AB}$ Jr, Reboussin DM: Psoriasis causes as much disability as other major medical diseases. J Am Acad Dermatol 1999;41:401407.

6 Ellis CN, Prendergast MM, Tokar M, Tong K: Quantifying costs associated with atopic dermatitis. J Manag Care Pharm 2003;9: 278-279.

7 Finlay AY: Quality of life in atopic dermatitis. J Am Acad Dermatol 2001;45:S64-S66.

8 Williams HC: Epidemiology of atopic dermatitis: recent advances and future predictions. Curr Probl Dermatol 1999;28:9-17.

9 Williams HC: Clinical practice. Atopic dermatitis. N Engl J Med 2005;352:2314-2324.
10 Seiffert K, Hilbert E, Schaechinger $H$, Zouboulis CC, Deter HC: Psychophysiological reactivity under mental stress in atopic dermatitis. Dermatology 2005;210:286-293.

11 Ayyalaraju RS, Finlay AY, Dykes PJ, Trent JT, Kirsner RS, Kerdel FA: Hospitalization for severe skin disease improves quality of life in the United Kingdom and the United States: a comparative study. J Am Acad Dermatol 2003;49:249-254.

12 Finlay AY, Khan GK: Dermatology Life Quality Index (DLQI) - A simple practical measure for routine clinical use. Clin Exp Dermatol 1994;19:210-216.

13 Krueger GG, Feldman SR, Camisa C, Duvic M, Elder JT, Gottlieb AB, Koo J, Krueger JG, Lebwohl M, Lowe N, Menter A, Morison WL, Prystowsky JH, Shupack JL, Taylor JR, Weinstein GD, Barton TL, Rolstad T, Day RM: Two considerations for patients with psoriasis and their clinicians: what defines mild, moderate, and severe psoriasis? What constitutes a clinically significant improvement when treating psoriasis? J Am Acad Dermatol 2000;43:281-285.

14 Lewis VJ, Finlay AY: Two decades experience of the Psoriasis Disability Index. Dermatology 2005;210:261-268.

15 Uttjek M, Dufaker M, Nygren L, Stenberg B: Determinants of quality of life in a psoriasis population in northern Sweden. Acta Derm Venereol 2004;84:37-43.

16 Finlay AY: Psoriasis from the patient's point of view. Arch Dermatol 2001;137:352-353.
17 Krueger G, Koo J, Lebwohl M, Menter A Stern RS, Rolstad T: The impact of psoriasis on quality of life: results of a $1998 \mathrm{Na}$ tional Psoriasis Foundation patient-membership survey. Arch Dermatol 2001;137: 280-284

18 Stern RS, Nijsten T, Feldman SR, Margolis DJ, Rolstad T: Psoriasis is common, carries a substantial burden even when not extensive, and is associated with widespread treatment dissatisfaction. J Investig Dermatol Symp Proc 2004;9:136-139.

19 Kurwa HA, Finlay AY: Dermatology in-patient management greatly improves life quality. Br J Dermatol 1995;133:575-578.

20 World Medical Association declaration of Helsinki. Recommendations guiding physicians in biomedical research involving human subjects. JAMA 1997;277:925926

21 Lewis V, Finlay AY: 10 years experience of the Dermatology Life Quality Index (DLQI). J Investig Dermatol Symp Proc 2004;9:169180.

22 Khilij FA, Gonzalez M, Finlay AY: Clinical meaning of change in Dermatology Life Quality Index scores. Br J Dermatol 2002; 147(suppl 62):50

23 Mazzotti E, Picardi A, Sampogna F, Sera F, Pasquini P, Abeni D: Sensitivity of the Dermatology Life Quality Index to clinical change in patients with psoriasis. Br J Dermatol 2003; 149:318-322. 
24 Fredriksson T, Pettersson U: Severe psoriasis - Oral therapy with a new retinoid. Dermatologica 1978;157:238-244.

25 Hanifin JM, Thurston M, Omoto M, Cherill R, Tofte SJ, Graeber M: The eczema area and severity index (EASI): assessment of reliability in atopic dermatitis. EASI Evaluator Group. Exp Dermatol 2001;10:11-18.

26 Naldi L, Svensson A, Diepgen T, Elsner P, Grob JJ, Coenraads PJ, Bavinck JN, Williams $\mathrm{H}$ : Randomized clinical trials for psoriasis 1977-2000: the EDEN survey. J Invest Dermatol 2003;120:738-741.
27 Barbier N, Paul C, Luger T, Allen R, De Prost Y, Papp K, Eichenfield LF, Cherill R, Hanifin J: Validation of the Eczema Area and Severity Index for atopic dermatitis in a cohort of 1,550 patients from the pimecrolimus cream $1 \%$ randomized controlled clinical trials programme. Br J Dermatol 2004;150:96102.

28 Schmitt J, Wozel G: The psoriasis area and severity index is the adequate criterion to define severity in chronic plaque-type psoriasis. Dermatology 2005;210:194-199.

29 Dupont WD, Plummer WD: PS power and sample size program available for free on the Internet. Control Clin Trials 1997;18:274.
30 Stata Corporation: Stata 8 Reference Manual. College Station, Stata Corporation, 2003.

31 Stata Corporation: Stata Statistical Software: Release 8.0. College Station, Stata Corporation, 2002.

32 Vensel E, Hilley T, Trent J, Taylor JR, Kirsner RS, Kerdel FA, Taylor JR, Schwartzberg JB: Sustained improvement of the quality of life of patients with psoriasis after hospitalization. J Am Acad Dermatol 2000;43:858860 . 